\title{
Discurso do Sujeito Coletivo e Análise de Conteúdo na abordagem qualitativa em
}

\section{Saúde}

\author{
Discourse of the Collective Subject and Content Analysis on qualitative aproach in Health \\ Discurso del Sujeto Colectivo y Análisis de Contenido en el enfoque qualitativo en Salud
}

\section{Resumo}

A abordagem qualitativa possui relação com a subjetividade, incluindo a perspectiva dos sujeitos implicados por meio do contato direto e pessoal entre o pesquisador e os agentes sociais. Algumas pesquisas qualitativas se caracterizam por análises de informações que não podem ser mensuradas, mas que visam o entendimento da linguagem e seus significados em suas formas e contextos de expressão. Neste artigo dirigido a pesquisadores iniciantes na abordagem qualitativa, objetivou-se apresentar o Discurso do Sujeito Coletivo e a Análise de Conteúdo de forma articulada à utilização da entrevista como opções para o desenvolvimento de pesquisas desta natureza. A partir de uma análise teórica e comparativa, verificou-se que existem métodos que se aproximam da possibilidade de responder as intenções da pesquisa, porém não existe um modelo universal aplicável para todos os casos e suficiente em si mesmo. O fundamental é que os pesquisadores se apropriem dos métodos e técnicas existentes, e realizem uma escolha consciente do caminho em que a análise será conduzida.

Palavras-chave: Pesquisa qualitativa; Análise de conteúdo; Discurso do sujeito coletivo; Representação social.

\begin{abstract}
The qualitative approach is related to subjectivity, including the perspective of the subjects involved through direct and personal contact between the researcher and the social agents. Some qualitative research are characterized by analyzes of information that can not be measured, but that aim at the understanding of language and its meanings in its forms and contexts of expression. In this article aimed at researchers who are new to the qualitative approach, the objective was to present the Collective Subject Discourse and Content Analysis in an articulated way to the use of the interview as options for the development of research of this nature. From a theoretical and comparative analysis, it was verified that there are methods that approach the possibility of responding to the intentions of the research, but there is no universal model applicable to all cases and sufficient. The key is that researchers take ownership of existing methods and techniques and make a conscious choice of the path in which the analysis will be conducted.
\end{abstract}

Keywords: Qualitative research; Content analysis; Discourse of the collective subject; Social representations.

\section{Resumen}

El abordaje cualitativo tiene relación con la subjetividade, incluyendo la perspectiva de los sujetos involucrados a través del contacto directo y personal entre el investigador y los agentes sociales. Algunas investigaciones cualitativas se caracterizan por análisis de informaciones que no pueden ser mensuradas, sino que apuntan al entendimiento del lenguaje y sus significados en sus formas y contextos de expresión. En este artículo dirigido a investigadores iniciantes en el abordaje cualitativo, se objetivó presentar el Discurso del Sujeto Colectivo y el Análisis de Contenido de forma articulada a la utilización de la entrevista como opciones para el desarrollo de investigaciones de esta naturaleza. A partir de un análisis teórico y comparativo, se verificó que existen métodos que se aproximan a la posibilidad de responder a las intenciones de la investigación, pero no existe un modelo universal aplicable para todos 
los casos y suficiente en sí mismo. Lo fundamental es que los investigadores se apropien de los métodos y técnicas existentes, y realicen una elección consciente del camino en que el análisis será conducido.

Palabras clave: Investigación cualitativa; Análisis de contenido; Discurso del sujeto colectivo; Representación social.

\section{Introdução}

A abordagem qualitativa se faz cada vez mais presente em estudos da saúde. Considerando que as questões de pesquisa se conectam aos problemas da existência humana, esse aumento pode ser entendido enquanto resposta aos desafios em todas as áreas do saber, uma vez que excederiam as potencialidades do modelo da ciência positiva (Bosi, 2012). Lambert e McKevitt (2002) também avaliam que há certa concepção corrente de que métodos qualitativos obtém conhecimento acerca de aspectos e questões inalcançáveis aos métodos quantitativos.

No tocante ao campo científico da saúde, a biomedicina se estruturou por uma base epistemológica hegemônica proveniente das revoluções científicas a partir do século XVI amparadas pela filosofia de René Descartes, Francis Bacon e August Comte (Camargo Jr, 1997; Santos, 2001). Neste modelo de cientificidade engendrado pela racionalidade moderna que se pautou nas doutrinas filosóficas cartesianas e positivistas, a matemática assumiu um papel central ao embasar dois axiomas da ciência moderna, quais sejam: "conhecer significa quantificar" e "o rigor científico afere-se pelo rigor das medições" (Santos, 2001, p. 15). No entanto, estes fundamentos e seus métodos têm se mostrado insuficientes para resolver velhos problemas, sobretudo de caráter coletivo e social, exigindo que a ciência ultrapasse explicações reducionistas para alcançar novos níveis de complexidade que atentem aos conjuntos dinâmicos de relações entre sistemas sociais, culturais e biológicos (Camargo Jr, 2008; Jonsson, 2010; Canesqui, 2018).

Para Creswell (2010), se a pesquisa quantitativa permite provar teorias objetivas por meio dedutivo, a investigação de cunho qualitativo assegura, por meio indutivo, conhecer, explicar e compreender em profundidade aspectos internos do fenômeno, inclusive as produções de sentido que indivíduos ou coletividades constroem e reproduzem em relação àquilo que lhes afetam ou no qual estão implicados.

$\mathrm{Na}$ abordagem qualitativa para a compreensão da natureza social do fenômeno saúde/doença, pesquisadores da área da saúde, comumente formados pelos pressupostos cartesianos, se deparam com opções de métodos e técnicas para a produção de informações frente aos quais se sentem indecisos acerca do caminho a ser trilhado. Em uma nova lógica de pesquisa, perseguidos pelo problema da subjetividade, desafiados a comprovar a representatividade de sua amostra, e diante da amplitude de possibilidades e caminhos teóricos para os quais não tiveram o olhar treinado e não dominam o saber-fazer, conjugar técnica com teoria faz da pesquisa qualitativa em saúde para jovens cientistas, uma arte a ser dominada (Fontanella, Ricas \& Turato, 2008; Víctora, 2011).

A pesquisa qualitativa diverge da quantitativa, na medida em que não objetiva medir os eventos estudados, mas obter uma descrição com força argumentativa que inclua a perspectiva dos sujeitos implicados por meio do contato direto e pessoal entre o pesquisador e os agentes sociais. Busca analisar respostas que não podem ser mensuradas podendo em muitos casos visar o entendimento da linguagem e seus significados em suas várias formas e contextos de expressão, debruçar-se em simbologias, motivações e dinâmicas das relações nas estruturas (Bosi, 2010; Minayo \& Sanches, 1993). Ressalta-se que neste tipo de investigação, pesquisadores não se preocupam apenas com os dados coletados e os resultados, mas com a construção e o entendimento do processo de pesquisa em si (Godoy, 1995). Interessam as relações de poder envolvidas na pesquisa já que esta se constrói em interação face a face e se constitui em momento específico de mobilização recíproca de intenções, opiniões e ações (Fraser, 2004).

A abordagem qualitativa engloba uma série de arranjos teóricos e metodológicos com técnicas de coleta de dados, propostas de sistematização para análise e conceitos. Dentre elas, destacamos o uso da técnica da entrevista para coleta de dados aliada à Teoria das Representações Sociais pelo Discurso do Sujeito Coletivo ou a Análise de Conteúdo. Estes arranjos 
conceituais e técnicos serão aqui objeto de breve análise comparativa evidenciando-se algumas potencialidades e limitações, vez que apresentam certa importância no desenvolvimento de pesquisas sociais qualitativas em saúde. Pretende-se com isso colaborar na formação de jovens pesquisadores oriundos das diversas profissões da área da saúde ainda iniciantes nas abordagens qualitativas do processo saúde/doença.

\section{Metodologia}

Esta revisão narrativa fundamentou-se na seguinte pergunta de pesquisa: "Quais as potencialidades e limitações e as similaridades e diferenças entre a técnica do Discurso do Sujeito Coletivo e a Análise de Conteúdo na pesquisa qualitativa em saúde?”. A revisão foi realizada por meio do acesso às bases de dados eletrônicas PubMed, Scientific Electronic Library Online (SciELO) e Biblioteca Virtual em Saúde (BVS). Foi conduzida ainda a exploração da literatura cinzenta, usando o Google Acadêmico. Os descritores empregados na estratégia de busca foram: Teoria das Representações Sociais, Análise de Conteúdo, Discurso do Sujeito Coletivo, Entrevista e Pesquisa Qualitativa. Foi realizada uma seleção inicial por títulos e resumos. Em seguida, os artigos selecionados foram obtidos na íntegra. Livros sobre a temática em questão também foram incluídos nesta revisão.

Em um primeiro momento, buscou-se apresentar a Teoria das Representações Sociais, o Discurso do Sujeito Coletivo, a Análise de Conteúdo e a técnica de entrevista, descrevendo suas características e fundamentos. Posteriormente, realizou-se análise crítica acerca das metodologias em questão, buscando compará-las em suas potencialidades e limitações.

\section{Resultados e Discussão}

\subsection{A teoria das representações sociais e o discurso do sujeito coletivo}

Para Moscovici (2003), as representações podem ser consideradas um conjunto de fenômenos, imagens, crenças e opiniões, em que o entrelaçamento destes elementos possibilita a atribuição de significados aos processos sociais e psicológicos. São uma modalidade específica de conhecimento com a função de elaboração do comportamento e de comunicação entre os indivíduos (Spink, 1995). As representações sociais são fenômenos complexos referentes ao processo pelos quais o sentido de um objeto é estruturado pelo sujeito no contexto de suas relações, em um processo dinâmico de compreensão e transformação da realidade.

Segundo Lefèvre e Lefèvre (2014), as representações sociais, enquanto conhecimentos do senso comum se fazem presentes nas opiniões ou postura de um sujeito em sua vida cotidiana. Podem então ser compreendidas como sínteses (acerca do desconhecido) que se aproximam da empiria, as quais podem ser reconhecidas sem grandes dificuldades pelo senso comum como conhecimentos familiares. Uma das formas de apresentar as representações sociais é por meio do Discurso do Sujeito Coletivo.

Desenvolvido por pesquisadores da Universidade de São Paulo (USP), o Discurso do Sujeito Coletivo (DSC) consiste em uma técnica de organização de dados qualitativos que permite, por meio de processos sistemáticos, agregar depoimentos sem reduzi-los a quantidades (Instituto de Pesquisa do Discurso do Sujeito Coletivo, 2015).

De acordo com Lefèvre e Lefèvre (2003), o DSC partiu da hipótese de que os indivíduos vivendo em sociedade compartilham ideias, crenças, valores e representações, bem como os sentidos, os conteúdos dos sentidos e os argumentos que compõem essas representações. Baseado nestas premissas estabeleceu-se um processo de organização dos depoimentos verbais provenientes de pesquisas sociais que utilizam questionários abertos ou semi-abertos, que por meio das figuras metodológicas permitem a construção dos DSCs.

A técnica do DSC é um processo composto por diversos momentos, efetuados através de operações realizadas sobre o material verbal coletado. Para que se produzam os DSCs, são necessárias quatro operações: as expressões-Chaves (E-CH), as 
quais são trechos dos depoimentos individuais que melhor descrevem seu conteúdo; as Idéias Centrais (ICs), que se constituem em fórmulas sintéticas que expressam os significados presentes nos depoimentos de cada resposta e nos grupos de respostas de diferentes indivíduos, que apresentam sentidos semelhantes; as Ancoragens (ACs), também descritas como fórmulas sintéticas, porém que descrevem as ideologias, valores, crenças, presentes no material verbal das respostas individuais ou agrupadas; e o Discurso do Sujeito Coletivo (DSC), o qual é composto pela união das E-CH presentes nos depoimentos com ICs ou ACs de sentido semelhante ou complementar, dando-lhes a forma de frases encadeadas (Lefèvre \& Lefèvre, 2005a).

Após a coleta das entrevistas, sua gravação e transcrição, deve-se proceder à tabulação dos dados baseada nas operações acima mencionadas. Inicialmente deve-se analisar cada questão, copiando integralmente a resposta de cada indivíduo, em seguida, as expressões-chave das ideias centrais ou das ancoragens devem ser sublinhadas. Na sequência, as ideias centrais e ancoragens de cada resposta são identificadas, agrupando-se depois aquelas de sentidos semelhantes. O último passo é a construção do DSC, unindo as expressões-chave do mesmo grupamento e sequenciando-as, de forma coesa e coerente, resultando em um painel de discursos de sujeitos coletivos, enunciados na primeira pessoa do singular sugerindo que a coletividade fala como um sujeito-indivíduo (Lefèvre \& Lefèvre, 2005b).

\subsection{A análise de conteúdo (AC) sob a perspectiva da pesquisa qualitativa}

Bardin (1977) define AC como um conjunto de instrumentos metodológicos e técnicas de análise das comunicações, que utiliza procedimentos sistemáticos e objetivos de descrição do conteúdo das mensagens. O trabalho da análise de conteúdo se define por regras lógicas de organização, categorização e tratamento de dados quantitativos ou qualitativos.

Com Bardin o principal enfoque nesse método passa a ser o de produzir inferências sobre as condições de produção da mensagem. Muitas vezes, a informação puramente descritiva sobre o conteúdo é de pouco valor, mas as comparações entre elas conferem ao método relevância teórica. Assim, produzir inferência significa, não somente produzir suposições subliminares acerca de determinada mensagem, mas embasá-las com pressupostos teóricos e situações concretas, que consideram o contexto social e histórico (Campos, 2004).

$\mathrm{Na}$ abordagem quantitativa utiliza-se enumeração por frequência, em que se contam as características repetidas no conteúdo do texto. Na qualitativa, considera-se a presença/ausência de alguma característica de conteúdo ou conjunto durante a mensagem. Assim, categorizam-se as unidades do texto (palavras ou frases), atribuindo uma expressão que represente a categoria (Caregnato \& Mutti, 2006).

Para o desenvolvimento do método da análise de conteúdo, diversos autores elencam distintas técnicas que podem ser utilizadas.

[...] São elas: análise temática ou categorial, análise de avaliação ou representacional, análise da enunciação, análise da expressão, análise das relações ou associações, análise do discurso, análise léxica ou sintática, análise transversal ou longitudinal, análise do geral para o particular, análise do particular para o geral, análise segundo o tipo de relação mantida com o objeto estudado, análise dimensional, análise de dupla categorização em quadro de dupla entrada, dentre outras (Oliveira, 2008, p.571).

Bardin (1977) afirma que a análise de conteúdo é composta de três grandes etapas: pré-análise, exploração do material e tratamento dos resultados, inferência e interpretação. A primeira fase é referente à organização, onde são geradas as hipóteses, objetivos e elaboração de indicadores que fundamentam a interpretação. Nessa fase, a leitura de todo material é imprescindível para apreender e organizar de forma não estruturada aspectos importantes para as próximas fases da análise, como a compreensão do contexto e as impressões e orientações que surgem a partir dele (Bardin, 1977; Campos, 2004). Na segunda etapa - de exploração do material -, faz-se a transformação do material pela sua codificação e categorização.

$\mathrm{Na}$ codificação, selecionam-se dados pela identificação de unidades de análise, que incluem palavras, frases, 
parágrafo, dentre outros elementos. Consiste na classificação dos elementos segundo suas semelhanças e diferenças, para posteriormente, na categorização, serem reagrupados baseando-se nas características comuns (Bardin, 1977). Nesta etapa, o investigador pode ser orientado pelas questões de pesquisa e adotar categorias a priori de sentido ou construir categorias a partir de sentidos emergentes do material analisado (Campos, 2004).

A terceira fase é o momento da reflexão crítica em que ocorrem as interpretações inferenciais. Na inferëncia se admite uma proposição - enunciado elaborado a partir do dado - pela sua aderência à outra já aceita como verdadeira. Estas proposições são interpretadas com aporte teórico conceitual que permite correlacioná-las com força argumentativa.

\subsection{A entrevista como técnica de coleta de dados}

A pesquisa qualitativa possui muitas técnicas de coleta de dados. Dentre elas, a entrevista merece destaque, visto que é uma das técnicas mais utilizadas em estudos científicos qualitativos se coadunando com a proposta de analisar as Representações Socais pelo emprego do Discurso do Sujeito Coletivo ou associada à Análise de Conteúdo. Contudo, registrase que há uma diversidade de usos ressoando em distinções metodológicas, mesmo nas abordagens qualitativas, "que repercutem [...] na sua estrutura, na definição de seus objetivos, no papel do entrevistador e do entrevistado, e nas formas de validação de seus resultados" (Fraser \& Gondim, 2004, p. 140).

Victora (2011) promove um debate necessário acerca do excesso de funcionalidade com que métodos popularizados pela abordagem qualitativa são empregados nas pesquisas em saúde. Suas preocupações procedem quando se considera a recorrência de estudos qualitativos em saúde com o uso da técnica de entrevista aliada à Análise de Conteúdo muitas vezes empregadas superficialmente e sem o suporte de esquemas conceituais mais encorpados. Para corroborar sua opinião, a autora aciona oportunamente Pierre Bourdieu para quem "É somente em função de um corpo de hipóteses derivado de um conjunto de pressuposições teóricas que um dado empírico qualquer pode funcionar como evidência” (Bourdieu, 1989, p, 24).

Constituindo-se em uma conversa dirigida e com uma intencionalidade definida, a entrevista na pesquisa qualitativa, ao focar na fala dos atores sociais, privilegia a palavra como símbolo das relações humanas (Haguette, 2001; Minayo, 2004). Permite atingir um nível de compreensão da realidade humana por meio das opiniões, crenças, valores, motivações e significados que as pessoas atribuem a si, aos outros e ao mundo circundante expresso por meio de fala que se transformará em texto a ser analisado pelo cientista. Ou seja, a finalidade é dar voz ao outro e compreender a partir de qual perspectiva se fala. Para tanto, o entrevistador deve assumir um papel menos diretivo (Fraser \& Gondim, 2004).

Dentre os tipos de entrevistas, as mais empregadas são as não-estruturadas e as semiestruturadas. A escolha de uma delas se relaciona com o grau de diretividade que se pretende seguir, variando desde a entrevista na qual se introduz o tema da pesquisa permitindo ao entrevistado discorrer livremente sobre ele, até a entrevista um pouco mais estruturada em que há um roteiro de tópicos que direciona sem impedir o aprofundamento de aspectos importantes (Bartholomew, Henderson \& Márcia, 2000).

Em se tratando do roteiro de perguntas aplicado, Lefèvre e Lefèvre (2005b) consideram como pergunta ideal, aquela que incita o entrevistado a elaborar um discurso que: responde àquilo que o pesquisador está investigando; que permite ao entrevistado responder ou discorrer liberado de expectativas ou coerções; que seja compreensível; não apresente um viés ideológico do pesquisador; e que tenha sido pré-testada com sujeitos semelhantes aos da pesquisa proposta.

Durante a análise das informações colhidas a partir das técnicas de coleta de dados, o material deve ser comparado concomitantemente com a literatura científica de referência, para que o tema seja articulado às produções científicas. Entretanto, a fala do entrevistado também é considerada como fonte de conhecimento e, como tal, deve ser valorizada integralmente evitando-se o enquadramento forçado em esquemas teóricos (Duarte, 2004; Víctora, 2011). A leitura flutuante, repetida e exaustiva das entrevistas após a transcrição atenta aos contextos de produção das falas, considerando-se os 
marcadores sociais de quem enuncia sentido (classe, gênero, etnia/raça e escolaridade) e as dinâmicas sociais que envolvem o objeto de pesquisa, são todas prerrogativas básicas que envolvem a fidedignidade dos dados qualitativos coletados diretamente pelo cientista por intermédio de entrevistas face a face.

A natureza dos dados qualitativos provenientes de entrevistas em profundidade se presta às análises igualmente em profundidade em que a regularidade matemática das informações importa menos que "uma lógica de (ir)regularidades" (Víctora, 2001, p. 108). Assim o conjunto das entrevistas pensado enquanto um universo de pesquisa que é definido intencionalmente orienta-se pela capacidade dos sujeitos responderem satisfatoriamente às perguntas ou elucidarem aspectos relevantes do objeto. Neste tipo de conversa dotada de uma intencionalidade, amparada por uma teoria sobre a realidade social do objeto, a reflexão crítica do "com quem e sobre o que se fala" e "como se conduz a entrevista" asseguram a validação científica e a representatividade explicativa do conjunto de entrevistas.

A produção do dado qualitativo por meio da entrevista e sua validação científica poderia, desta forma, seguindo a proposta de Correia (2013, p. 268-269) ser permeada por: a) considerar metodologicamente um processo de "racionalização sobre o objeto de estudo como objeto-sujeito" tendo em vista que ambos (pesquisador - pesquisado são de mesma natureza); b) a "articulação entre produção discursiva dos sentidos e a compreensão dos conteúdos de interação" de forma a evitar discursos artificiais considerando-se que o pesquisador é um outsider do contexto imediato pesquisado; 3) a "racionalização sobre as condições sociais de produção do conhecimento" por meio de uma autovigilância na tomada de decisões no curso da pesquisa, bem como a explicitação clara dos procedimentos técnicos e éticos aos leitores.

Um dos critérios relevantes na validação científica de uma pesquisa define-se pela amostragem (Malterud, 2001). Mays e Pope (1995) atribuem como amostragem teórica o processo de definição e seleção dos elementos que constituem o universo de pesquisa a partir do encadeamento teórico que alinha pela amostragem intencional os atributos sociais desejáveis e características intrínsecas capazes de gerar explicações pertinentes ao objeto. Este procedimento igualmente se mostra eficiente quando do fechamento amostral por saturação do universo de pesquisa por meio de entrevista com todos os agentes sociais pertinentes ao caso/organização/grupo social investigado (Machado, 2007). Esta definição nos ajuda a compreender como em muitos casos, a definição a priore de um número mínimo ou máximo de entrevistados não tem aplicação prática em estudos desta natureza.

No desenvolvimento de pesquisas qualitativas, a representatividade é assumida pelo valor da fala do indivíduo, o que ela é capaz de revelar, sua dimensão social e profundidade subjetiva, e a capacidade de responder às perguntas norteadoras da investigação. Ademais sendo a amostragem um dos mecanismos de validação científica, importa referir que "diferentes paradigmas científicos comportam e prescrevem diferentes tipos de construção de amostras" (Fontanella, Ricas \& Turato, 2008, p.18). No caso do fechamento amostral em pesquisas qualitativas, Glaser e Strauss (1967), ao cunharem o conceito de saturação teórica pretendiam dar conta da suficiência de entrevistas em termos de representatividade considerando a confiança empírica na saturação da categoria teórica.

Assim a quantidade de entrevistas é dada como suficiente na medida em que oferece potencial explicativo convincente dispensando elevado número de pessoas para que determinados fenômenos sejam entendidos e interpretados, isto porque,

[...] cada agente, quer ele saiba ou não, quer ele queira ou não, é produtor e reprodutor de sentido objetivo: porque suas ações e suas obras são o produto de um modus operandi do qual ele não é o produtor e do qual não tem o domínio consciente [...], encerram uma "intenção objetiva" que ultrapassa sempre suas intenções conscientes (Bourdieu, 1983, p. 72).

Pela entrevista pretende-se construir ligações entre a história individual e a história social, entre singularidade e a 
universalidade, entre a subjetividade e o coletivo. Portanto, é através da palavra que a abordagem qualitativa produz a significação dos objetos:

[...] a fala torna-se reveladora de condições estruturais, de sistemas de valores, normas e símbolos (sendo ela mesma um deles), e, ao mesmo tempo, possui a magia de transmitir, através de um porta-voz (o entrevistado), representações de grupos determinados em condições históricas, socioeconômicas e culturais específicas (Minayo \& Sanches, 1993, p. 245).

Deste modo, os sujeitos representam determinados contextos e são considerados no objeto da pesquisa por possibilitarem aos pesquisadores, através da fala, o entendimento e interpretação dos fenômenos que estudam.

O método qualitativo é considerado êmico, ou seja, não tem como foco a confirmação de teorias já existentes, mas sim trazer à tona a originalidade do conhecimento adquirido (Morse \& Field, 2005). Por fim, ressalta-se que a subjetividade constituinte das falas dos entrevistados e como parte integrante do processo de interação pesquisador/a - pesquisado/a traz particularidades a esta técnica tornando o papel do entrevistador crucial em todo o processo de análise e avaliação (Britto Jr \& Feris Jr, 2011). A densidade do material empírico, sua riqueza e potencialidade explicativa dependem fortemente do preparo teórico do pesquisador aliado a um processo reflexivo intenso acerca de sua própria subjetividade e valores pessoais de modo a evitar vieses na leitura da realidade estudada.

\subsection{Discurso do sujeito coletivo versus análise de conteúdo: uma abordagem crítica}

A análise de dados requer atenção e cautela do pesquisador na escolha do método que será utilizado, uma vez que esta deverá permitir a exploração dos dados da forma mais consistente possível (Campos, 2004). Tal escolha “[...] deve obrigatoriamente proporcionar um olhar multifacetado sobre a totalidade dos dados recolhidos no período de coleta (corpus) [...]" (Campos, 2004, p. 611). Desta forma, é necessário ponderar qual o objetivo da pesquisa para que seja respondido da melhor maneira, e assim optar pelo tratamento de dados mais adequado.

O Discurso do Sujeito Coletivo apresenta vários aspectos positivos em sua aplicação. Segundo Lefèvre e Lefèvre (2005b), a apresentação dos resultados na forma de discurso confere espontaneidade e naturalidade às representações sociais. É, portanto, uma inovação nas pesquisas contendo questões abertas, uma vez que seus resultados são apresentados discursivamente e não na forma de categorias. Outras vantagens se devem ao fato de ser semanticamente rico, apresentando conteúdos significativos e seus detalhamentos acerca de uma mesma opinião; pela possibilidade de descrever em escala coletiva os argumentos associados à opinião; e pela apresentação de resultados mais densos (Lefèvre \& Lefèvre, $2005 a$ ).

Para Lefèvre e Lefèvre (2005a), quando o pesquisador soma as opiniões individuais por meio da categorização pura, ele está transgredindo a natureza discursiva da opinião coletiva, visto que desta soma não resulta um discurso, mas uma categoria que não apresenta sentido da opinião coletiva. Assim, uma opinião para ser coletiva precisa ser somada indutivamente e ter preservada no produto sua natureza discursiva, composta não somente pela categoria, mas também pelo conteúdo das respostas individuais.

Já Bardin (1977) traz outra concepção para as categorias que são utilizadas no processo da análise de conteúdo. Para a autora, a categorização “[...] é uma operação de classificação de elementos constitutivos de um conjunto, por diferenciação e, seguidamente, por reagrupamento segundo o gênero (analogia), com os critérios previamente definidos” (Bardin, 1977, p.117). As categorias são consideradas classes constituídas por grupos de elementos que apresentam características em comum com outros e um título genérico para representar o grupo. A categorização destes elementos pode ser feita baseada em critérios, como: semântica (temas iguais), sintática (verbos, adjetivos), léxica (palavras sinônimas, sentidos similares) e expressiva (categorias que classificam as diversas perturbações da linguagem). 
Para Bardin (1977, p.119), “[...] A análise de conteúdo assenta implicitamente na crença de que a categorização (passagem de dados brutos a dados organizados) não introduz desvios (por excesso ou por recusa) no material, mas que dá a conhecer índices invisíveis, ao nível dos dados brutos". A autora defende que para haver categorias potenciais, as seguintes qualidades devem estar presentes: a exclusão mútua em que os elementos destacados não correspondam a mais de uma categoria; a homogeneidade, em que a organização das categorias deve ser feita a partir de um único princípio/critério; a pertinência, que diz respeito à relação entre as intenções da pesquisa com as categorias definidas; a objetividade e fidelidade, em que as categorias devem ser bem estabelecidas, evitando distorção e influência da subjetividade dos pesquisadores; a produtividade, em que as categorias possibilitam resultados produtivos, com bons índices de inferência e dados concisos. Desta forma, contraditoriamente à percepção de categorias abordada por Lefêvre e Lefèvre (2005a), Bardin (1977) considera que essa técnica é eficiente no processo de análise de dados de pesquisas científicas.

Retomando o DSC, a coletividade ao falar na primeira pessoa do singular, expressa o regime regular das representações sociais e proporciona as próprias representações sociais como fatos coletivos referentes a coletividades qualitativas dos discursos, e quantitativas dos indivíduos (Lefèvre \& Lefèvre, 2006). Assim, este indivíduo/coletivo é um sujeito que carrega não apenas os conteúdos da representação social que pessoalmente adota, mas também os conteúdos dos outros (Lefèvre \& Lefèvre, 2014).

Além disso, Lefèvre e Lefèvre (2012) apontam como vantagem a possibilidade de conhecer em detalhes o pensamento das coletividades sobre dado assunto e, ao mesmo tempo, conhecer o grau de compartilhamento de cada opinião. Ou seja, após obter os discursos do sujeito coletivo, é possível saber o peso relativo, expresso em porcentagens, desse DSC. A pesquisa pode ser, portanto, qualiquantitativa. Dessa forma, assegura-se a natureza discursiva e qualitativa da opinião; e a dimensão quantitativa, relacionada com a representatividade e generalização dos resultados (Lefèvre \& Lefèvre, 2005b).

Para Gondim e Fischer (2009), a associação entre quantidade e qualidade, avaliando a frequência com que um dado discurso é compartilhado, levaria a acreditar que o DSC não seria uma metodologia indicada para entrevistas em profundidade. Para as autoras, a quantificação não deve ser o principal critério do DSC, uma vez que a força do discurso reside na amplitude dos significados. Sobre isso, elas mencionam que "[...] se o sentido é o mesmo, não importa se as expressões-chave só apareceram em um discurso ou em vários, pois basta encaixá-las de modo que deem sentido às demais expressões chave para torná-las parte do discurso coletivo." (Gondim \& Fischer, 2009, p.16). As autoras defendem, ainda, que todo discurso individual é um discurso socialmente compartilhado, uma vez que seu sentido está vinculado ao contexto social de produção (Gondim \& Fischer, 2009). Além disso, acreditam que o discurso deve ser construído na terceira pessoa, a qual representa os outros presentes na pessoa.

Em relação ao método da análise de conteúdo proposto por Bardin (1977), ele pode ser aplicado em diversos contextos. Sobre isso, vale enfatizar que:

[...] a análise de conteúdo permite o acesso a diversos conteúdos, explícitos ou não, presentes em um texto, sejam eles expressos na axiologia subjacente ao texto analisado; implicação do contexto político nos discursos; exploração da moralidade de dada época; análise das representações sociais sobre determinado objeto; inconsciente coletivo em determinado tema; repertório semântico ou sintático de determinado grupo social ou profissional; análise da comunicação cotidiana, seja ela verbal ou escrita, entre outros (Oliveira, 2008, p.570).

A escolha deste método no desenvolvimento das pesquisas científicas pode se dar devido à importância e necessidade da leitura e compreensão dos significados e sentidos para além das falas em si (Cavalcante, Calixto \& Pinheiro, 2014). Desta forma, o entendimento dos elementos e categorias encontradas é de suma importância para a clareza da pesquisa. Assim, a inferência, última etapa do processo da análise de conteúdo, confere ao método relevância teórica. Isto porque, produzir 
inferência possibilita a valorização da informação exposta, superando uma mera suposição acerca do assunto, mas sim o embasamento teórico de acordo com diversas concepções de mundo (Campos, 2004).

Tanto o DSC, quanto a Análise de Conteúdo estão inseridos em um quadro de propostas metodológicas que visam extrair, por meio da análise dos dados coletados, núcleos de sentidos e significados. No entanto a primeira difere desta última pela maneira como realiza esta extração, em particular, pelo uso da primeira pessoa do singular para transmitir a opinião coletiva (Lefèvre \& Lefèvre, 2010). Outra diferença está no fato de o DSC ter como objeto de análise o próprio discurso, buscando identificar sentidos e circunscrevê-los na teoria das representações sociais (Gondim \& Fischer, 2009); enquanto "[...] a AC trabalha com o conteúdo, ou seja, com a materialidade linguística, através das condições empíricas do texto, estabelecendo categorias para sua interpretação" (Caregnato \& Mutti, 2006, p.683). Tal fato reflete na apresentação final dos resultados, em que no DSC há a formulação de um painel de discursos de sujeitos coletivos; ao passo que na análise de conteúdo, são apresentadas as categorias identificadas. Finalmente, para além destes aspectos, sinaliza-se que os dois métodos se assemelham pelo fato de ambos poderem ser qualitativo e quantitativo; e por utilizarem a entrevista como possibilidade para a coleta de dados.

\section{Considerações Finais}

As metodologias qualitativas são essenciais para o desvelamento dos processos sociais complexos que produzem e afetam a saúde. Para Minayo (2004), a explicação e compreensão deste campo envolve a quantificação, ao mesmo tempo em que a ultrapassa quando o que se pretende é perscrutar as dimensões profundas e significativas que não podem ser expressas em variáveis.

A abordagem qualitativa é o caminho metodológico de validade heurística quando se pretende explicar a saúde em suas dimensões sociais, contudo requer um entendimento aguçado da realidade social e uma formação específica para os pesquisadores, visto que estes irão adentrar em um universo de conhecimento para o qual não foram formados tendo em vista o modelo hegemônico de formação dos profissionais da saúde, centrado na biomedicina.

A partir de um ensaio teórico e comparativo, analisou-se que o Discurso do Sujeito Coletivo e a Análise de Conteúdo podem ser opções de propostas metodológicas interessantes no campo da pesquisa qualitativa em saúde, sendo ambas aliadas à técnica da entrevista para a coleta de dados.

As representações acerca de doença, corpo, cuidado e atenção à saúde, bem como dos processos de trabalho que envolvem a educação e a execução de políticas públicas são elementos sociais constituintes do campo da saúde que precisam ser continuamente investigados. As representações são formas de conhecimento do senso comum e permitem transformar o desconhecido em conhecido, o não familiar em familiar, o estranho e perturbador em algo próximo (Horochovski, 2004). A relevância sociológica do estudo das representações sociais, desse modo, está no fato delas fundamentarem práticas e atitudes dos indivíduos, uns em relação aos outros, no contexto social e naquilo que lhes afeta (Moscovici, 2003).

Evidenciou-se que a opinião coletiva expressa na forma de DSC apresenta grandes vantagens, na medida em que é semanticamente rica e identifica conteúdos significativos. Permite descrever, em escala coletiva, as justificativas associadas à opinião e exige do pesquisador, quando da tabulação dos depoimentos, a empreender um raciocínio discursivo que torna os resultados mais densos (Lefèvre \& Lefèvre, 2005a).

Em relação à análise de conteúdo, foi possível apreender que o método apresenta processos estruturados que permitem a descrição do conteúdo dos dados coletados, e, por meio das categorias criadas, possibilita a identificação de elementos relevantes que posteriormente serão analisados e embasados teoricamente por meio da inferência teórica. Desta forma, o método apresenta legitimidade e relevância no âmbito das pesquisas qualitativas em saúde.

Por fim, sugere-se que encontrar um modelo único e ideal para interpretar os dados em estudos qualitativos é ilusório. 
Existem métodos que se aproximam da possibilidade de responder as intenções da pesquisa, porém não existe um modelo universal aplicável para todos os casos e suficiente em si mesmo (Kemmis \& Mactaggart, 2000; Cavalcante, Calixto \& Pinheiro, 2014). O fundamental é que pesquisadores envolvidos se apropriem dos vários métodos e técnicas existentes, para que sua escolha seja consciente e responsável acerca do caminho que a análise será conduzida (Caregnato \& Mutti, 2006).

Espera-se que este estudo contribua para a formação de pesquisadores das diversas áreas da saúde ainda iniciantes nas pesquisas com abordagem qualitativa. Ademais, este estudo pode encorajar o desenvolvimento de novas pesquisas sobre a temática, por exemplo, acerca do nível de conhecimento dos profissionais de saúde sobre as técnicas de pesquisa qualitativa.

\section{Referências}

Bardin, L. (1977). Análise de conteúdo. Edições 70.

Bartholomew, K., Henderson, A. J. Z., \& Márcia, J. E. Coding semistructured interviews in social psychology research. In: Reis, H. T.; Judd, C. M. (2000). Handbook of research methods in social and personality psychology. UK: Cambridge University Press.

Bosi, M. L. M. (2012). Pesquisa Qualitativa em Saúde Coletiva: Panoramas e Desafios. Ciência e Saúde Coletiva, 17(3), 575-586.

Bourdieu, P. Esboço da teoria da prática. In: Ortiz, R. (Org.) (1983). Pierre Bourdieu/Sociologia. Coleção Grandes Cientistas Sociais. Ática.

Bourdieu, P. (1989). O poder simbólico. Bertand Brasil AS/Difel.

Britto Junior, A. F., \& Feres Junior, N. (2011) A utilização da técnica da entrevista em trabalhos científicos. Evidência, 7(7), 237-250.

Camargo Junior, K. R. de. (1997). A biomedicina. Physis. Revista de Saúde Coletiva, 7(1), 45-69.

Camargo Junior, K. R. (2008). A relevância do uso de técnicas qualitativas em pesquisas sobre a biomedicina. Ciência e Saúde Coletiva, 13(4), 1327-1330.

Campos, C. J. G. (2004). Método de análise de conteúdo: ferramenta para a análise de dados qualitativos no campo da saúde. Revista Brasileira de Enfermagem, 57(5), 611-614.

Canesqui, A. M. (2018). Considerações sobre a experiência do adoecimento e do sofrimento. Ciência e Saúde Coletiva, $23(8), 2466$.

Caregnato, R. C. A., \& Mutti, R. (2006). Pesquisa qualitativa: análise de discurso versus análise de conteúdo. Texto Contexto Enfermagem, 15(4), 679-684.

Cavalcante, R. B., Calixto, P., \& Pinheiro, M. M. K. (2014). Análise de Conteúdo: considerações gerais, relações com a pergunta de pesquisa, possibilidades e limitações do método. Revista Informação e Sociedade, 24(1), 13-18.

Correia, T. (2013). Interpretação e validação científica em pesquisa qualitativa. Interface (Botucatu), 17(45), 263-74.

Creswell, J. W. (2010). Projeto de Pesquisa: Métodos Qualitativo, Quantitativo e Misto. (3a ed.), Artmed.

Duarte, R. (2004). Entrevistas em pesquisas qualitativas. Educar, 24, 213-225.

Fontanella, B. J. B., Ricas, J., \& Turato, E. R. (2008). Amostragem por saturação em pesquisas qualitativas em saúde: contribuições teóricas. Cadernos de Saúde Pública, 24(1), 17-27.

Fraser, M. T. D., \& Gondim, S. M. G. (2004). Da fala do outro ao texto negociado: Discussões sobre a entrevista na pesquisa qualitativa. Paidéia, 14(28), 139152.

Glaser, B. G., \& Strauss, A. L. (1967). The discovery of grounded theory: strategies for qualitative research. Aldine de Gruyter.

Godoy, A.S. (1995). Introdução à Pesquisa Qualitativa e suas Possibilidades. Revista de Administração de Empresas, 35(2), 57-63.

Gondim, S.M.G., \& Fischer, T. (2009). O discurso, a análise de discurso e a metodologia do discurso do sujeito coletivo na gestão intercultural. Cadernos Gestão Social, 2(1), 9-26.

Haguette, T.M.F. (2001). Metodologias qualitativas na sociologia. Vozes.

Horochovski, M.T.H. (2004). Representações Sociais: Delineamentos de uma categoria analítica. Revista Em Tese, 2(1), 92-106.

Jonsson, U. (2010). Competencia de paradigmas en la Nutrición aplicada: Ya no se trata de ciência, sino de ideologia y política. In: Observatorio del Derecho a la Alimentación y a la Nutrición.Reinheim: LokayDruck.

Kemmis, S., \& Mctaggart, R. (2000). Participatory action research. In: Denzin; Lincoln, Y.S. (orgs.). Handbook of qualitative research. London: Sage Publications Inc.

Lambert, H., \& Mckevitt, C. (2002). Anthropology in health research: from qualitative methods to multidisciplinarity. British Medical Journal, 325, 210-213. 
Research, Society and Development, v. 10, n. 1, e57310112098, 2021

(CC BY 4.0) | ISSN 2525-3409 | DOI: http://dx.doi.org/10.33448/rsd-v10i1.12098

Lefevre, F., \& Lefevre, A. M. C. (2014). Discurso do Sujeito Coletivo: Representações Sociais e Intervenções Comunicativas. Texto Contexto Enfermagem, 23(2), 502-507.

Lefevre, F., \& Lefevre, A. M. C. (2005a) Depoimentos e Discursos: uma proposta de análise em pesquisa social. Líber Livro Editora.

Lefevre, F., \& Lefevre, A. M. C. (2005b). O discurso do sujeito coletivo: um novo enfoque em pesquisa qualitativa (desdobramentos). Edusc.

Lefevre, F., \& Lefevre, A. M. C. (2003). O pensamento coletivo como soma qualitativa. http://www.fsp.usp.br/qualisaude/soma\%20qualitativa\%209\%20de\%20fevereiro\%20de\%202004.htm

Lefevre, F., \& Lefevre, A. M. C. (2006). O Sujeito Coletivo que fala. Interface, 10(20), 517-524.

Lefevre, F., \& Lefevre, A. M. C. (2012). Pesquisa de Representação Social: Um enfoque Qualiquantitativo. (2a ed.), Liber Livro Editora.

Lefèvre, F. et al. (2010). O discurso do sujeito coletivo como eu ampliado: aplicando a proposta em pesquisa sobre a pílula do dia seguinte. Rev Bras Crescimento Desenvolv Hum, 20(3), 798-808.

Machado, M. N. M. (2007). Entrevistas de pesquisa não-estruturadas e semi-estruturadas In: Administração, Metodologia, Organizações, Estratégia. (2a ed.), Curitiba: Juruá Editora.

Malterud, K. (2001). Qualitative research: standards, challenges, and guidelines. Lancet, 358, 483-8.

Mays, N., \& Pope, C. (1995). Qualitative research: rigour and qualitative research. British Medical Journal, 311, 109-112.

Minayo, M. C. S. (2004). O desafio do conhecimento: pesquisa qualitativa em saúde. (8a ed.), Editora Hucitec.

Minayo, M. C. S., \& Sanches, O. (1993) Quantitativo-Qualitativo: Oposição ou Complementaridade? Cadernos de Saúde Pública, 9(3), $239-262$.

Morse, J. M., \& Field, P. A. (2005). Qualitative research methods for health professionals. In: Turato, E. R. Métodos qualitativos e quantitativos na área da saúde: definições, diferenças e seus objetos de pesquisa. Revista de Saúde Pública, 39(3), 507-514.

Moscovici, S. (2003). Representações Sociais: investigações em psicologia social. Petrópolis: Vozes.

Oliveira, D. C. de. (2008). Análise de Conteúdo Temático-Categorial: uma Proposta de Sistematização. Revista de Enfermagem da UERJ, 16(4), 569-576.

Santos, B. S. (2001). Um discurso sobre as ciências. (12a ed.), Edições Afrontamento.

Spink, M. J. P. (1995). O conhecimento no cotidiano: as representações sociais na perspectiva da psicologia social. Brasiliense.

Víctora, C. G. (2011). Uma Ciência Replicante: a ausência de uma discussão sobre o método, a ética e o discurso. Saúde e Sociedade, 20(1), 104-112. 